\title{
ESTUDO SOBRE A SAZONALIDADE DO PRODUTO MACARRÃO NO MERCADO VAREJISTA DO PARÁ
}

\author{
Gisalda Carvalho Filgueiras ${ }^{1}$; Antônio Cordeiro de Santana ${ }^{2}$; Cyntia Meireles de \\ Oliveira $^{3}$; Edney Saraiva Monteiro ${ }^{4}$. \\ ${ }^{1}$ Professora, Doutora do Instituto de Ciências Sociais Aplicadas (ICSA) da Universidade Federal do Pará, \\ Belém, Pará, Brasil, gisaldaf@yahoo.com.br \\ ${ }^{2}$ Professor, Doutor do Instituto Socioambiental e dos Recursos Hídricos (ISARH) da Universidade Federal Rural \\ da Amazônia (UFRA), Belém, Pará, Brasil, acsantana@superig.com.br \\ ${ }^{3}$ Professora, Doutora do ISARH da UFRA, Belém, Pará, Brasil, cyntiamei@ hotmail.com \\ ${ }^{4}$ Mestrando em Economia Rural pela Universidade Federal do Ceará, Fortaleza, Ceará, Brasil.
}

\begin{abstract}
RESUMO: O produto macarrão é um importante componente da cesta básica do brasileiro, contudo, nos últimos anos, tem sofrido aumento no seu preço, em virtude da variação do preço do trigo no mercado internacional. Este aumento tem nítido efeito sobre a variação do preço do macarrão no país, considerando, principalmente, que o Brasil importa grande parte do trigo utilizado na fabricação de pães, massas, biscoitos entre outros. Dessa feita, estimaram-se os Índices Estacionais do macarrão em uma série histórica de janeiro de 2000 a junho de 2007. A análise constou do Índice Estacional Médio, Índice Estacional Verdadeiro, Limites Inferiores e Superiores dos preços do macarrão ao longo de um ano, bem como análise de Amplitude e Índice Cíclico. Este estudo pode auxiliar no planejamento e comercialização das empresas que transacionam esse produto considerando a melhor época para formação de estoque.
\end{abstract}

PALAVRAS-CHAVE: comercialização, formação de estoques, planejamento.

\section{STUDY ON THE SEASONAL OF THE PRODUCT MACARONI IN THE RETAIL MARKET IN THE STATE OF PARÁ}

\begin{abstract}
The macaroni product is an important component of the diet of the Brazilian, but in recent years has been an increase in their prices due to the variation in the price of wheat in the international market. This sharp increase has no effect on the setting of the price of pasta in the country, considering, mainly, that Brazil imports most of the wheat used to make breads, pastas, cookies and more. This time, it was estimated the seasonal index's of pasta in a historical series from January 2000 to June 2007. The analysis consisted of deciduous East Index, Index Seasonal True, upper and lower limits in the price of pasta over a year and analysis of amplitude and Cyclical Index. This study may assist in planning and marketing companies that sell this product considering the best time for training stock.
\end{abstract}

KEY-WORDS: marketing, planning, stock of building.

\section{INTRODUÇÃO}

O conhecimento da variação estacional dos preços, de acordo com Hoffmann (1998), é de relevante importância para a orientação dos produtores agrícolas e dos comerciantes, assim como, para orientar a formulação de política agrícola de comercialização das 
safras por parte do governo. No caso do próprio consumidor, esse conhecimento também é de interesse para escolher a melhor ocasião de efetuar suas compras, considerando, principalmente, consumidores que compram no atacado como cooperativas de consumo, hospitais e hotéis. Acrescente-se ainda que, o conhecimento do Índice de Variação Estacional do preço de um produto agropecuário é essencial para a previsão de seu preço em determinada época do ano.

Uma série temporal é um conjunto de observações ordenadas em intervalos de tempo comumente iguais. Essas observações apresentam dependência serial e constituem um dos objetivos do estudo de séries temporais, o qual corresponde analisar e modelar essa dependência. Ademais, o fenômeno sazonal é definido como aquele que ocorre regularmente em uma série histórica, entretanto, sua estimativa não é simples, já que, ela necessita compatibilizar a questão conceitual do fenômeno em estudo com a estatística (LATORRE; CARDOSO, 2001).

Este trabalho tem o propósito de utilizar o modelo clássico de séries temporais para analisar o comportamento sazonal da série de preços do macarrão no mercado varejista do estado do Pará. O macarrão talvez seja a principal massa alimentícia da dieta dos consumidores brasileiros. Sua importância alimentar está nas seguintes propriedades organolépticas: pobre em gordura e açúcar, boa fonte de carboidratos, proteínas, vitamina $\mathrm{B}$, ferro, zinco e outros traços de elementos, além das fibras alimentares.

O macarrão é fabricado a partir do trigo, produto que o Brasil ainda não é autossuficiente, portanto, depende das importações oriundas, principalmente, da Argentina, o mais importante país produtor da América Latina.

Vale ressaltar que, atualmente, configura-se uma crise de alta de preços do produto trigo, que por sua vez afetará o preço de todos os seus derivados (pão, macarrão, biscoito, etc.), caso não haja substituições de países importadores, já que os preços atuais da Argentina se encontram em um dos patamares mais altos nos últimos 12 anos (SAMORA, 2007), ou seja, em média 100 dólares a mais do que os preços praticados na mesma época do ano passado. Por outro lado, ressalta-se que o produto argentino (trigo), tem, nos últimos anos, atendido mais da metade das necessidades anuais do Brasil.

A safra nacional começa em setembro e se estende até dezembro e, com a ampliação da oferta, espera-se que os preços recuem. A alta dos preços do trigo argentino, na verdade, se deve a uma alta global deste produto no mercado 
internacional devido a conjunturas adversas à produção, como clima e, consequentemente, queda da produção/oferta.

Em nível mundial, desde a safra 2001/2002, a União Européia (EU-25) é a maior produtora, seguida da China, Índia, Estados Unidos da América (USA), Rússia, Canadá, Austrália e outros (AGRIANUAL, 2007). A produção da Argentina situa-se no patamar de 12.500 toneladas (t) (AGRIANUAL, 2007; CONAB, 2007).

Do lado do consumo, as maiores absorções do produto devem-se à EU-25, seguida da China, Índia, Rússia e USA. Vale sublinhar que, estes países na safra 2004/2005 consumiram um montante de 607.291 toneladas, o que correspondeu a 97,29\% da produção total (624.190 t.), cujo estoque final ficou em $147.963 \mathrm{t}$ (CONAB, 2007).

No Brasil, os maiores produtores são os estados da Região Sul (Paraná-PR, Rio Grande do Sul - RS e Santa Catarina - SC), com uma área plantada de 2.181,6 mil hectares (ha), para a safra 2005/2006. Mais de $90 \%$ da produção brasileira de trigo corresponde aos estados do Paraná e Rio Grande do Sul. O Sudeste (Minas Gerais MG e São Paulo - SP) plantou 70,8 ha, na mesma safra. Contudo, para o mesmo período, a maior produtividade foi do Nordeste (Bahia), com $5.000 \mathrm{~kg} / \mathrm{ha}$, praticamente igual a do Sudeste (MG), com $4.360 \mathrm{~kg} / \mathrm{ha}$ (IBGE, 2008).

No que diz respeito ao market-share na produção de massas, em 2004 ficou assim: $40 \%$ da União Européia; $16 \%$ do restante da Europa; $23 \%$ da América do Sul e Central; $13 \%$ da América do Norte; $5 \%$ da África; $2 \%$ da Ásia e; $1 \%$ da Oceania (AGRIANUAL, 2007; ABIMA, 2008).

Em termos de produção mundial de massas, a Itália desponta como o primeiro produtor (3 milhões de toneladas/ano), seguido dos Estados Unidos (1,17 milhões de toneladas/ano). O Brasil aparece como o terceiro país em produção de massas de macarrão, com um milhão de toneladas. Isto corresponde, segundo a Associação Brasileira das Indústrias de Massas Alimentícias - ABIMA (2008), a um faturamento de $\mathrm{R} \$ 2,8$ bilhões, gerando cerca de 25.000 empregos diretos.

Quanto ao consumo mundial de massa, a Itália desponta como a maior, com 28,0 kg/hab./ano, seguida da Venezuela (12,7 kg/hab./ano), Tunísia (11,7 kg/hab./ano), Suíça $(10,1 \mathrm{~kg} /$ hab./ano) e, em quinta posição, os Estados Unidos com 9,0 kg/ hab./ano. No Brasil, o consumo do macarrão é considerado baixo, pois não chega a $6,4 \mathrm{~kg} /$ hab./ano (ABIMA, 2008).

Não obstante a importância do macarrão na dieta alimentar do brasileiro, 
não foram identificados trabalhos científicos analisando o padrão sazonal dos preços deste produto. Este trabalho, portanto, se justifica pelo pioneirismo e, principalmente, pelas informações e conhecimento gerados sobre o padrão estacional de comportamento do preço do macarrão. Conforme Santana e Amin (2002) esse tipo de estudo é de grande interesse dos órgãos de planejamento e controle dos preços dos alimentos e dos moinhos e supermercados que transacionam esse produto.

Considerando a relevância do produto macarrão na dieta humana e o fato da agroindústria de massas alimentícias apresentar forte capacidade de geração de emprego e renda, o objetivo deste trabalho foi analisar o comportamento sazonal dos preços de varejo desse produto no mercado paraense, com base em uma série histórica de janeiro de 2000 a junho de 2007, disponibilizada pela Secretaria de Planejamento, Orçamento e Finanças do Estado do Pará (SEPOF).

\section{EVOLUÇÃO DA PRODUÇÃO} MUNDIAL, IMPORTAÇÃO E CONSUMO DE TRIGO NO MUNDO E NO BRASIL

Em função da não disponibilidade de dados históricos sobre a produção e consumo de macarrão, fez-se uma análise do comportamento evolutivo do mercado de trigo, matéria-prima da produção de farinha utilizada na fabricação de pães e macarrão, entre uma gama de outros produtos. Como o trigo é o principal item da produção do macarrão, seu comportamento tende a se traduzir nas variações dos preços do macarrão, sobretudo por causa da dependência das importações.

A produção de trigo no mundo já foi maior, em termos de área colhida, como se pode observar na Tabela 1. Na safra de 1997/1998 a área colhida foi de 228.385 mil hectares e na última safra (2006/2007) chegou-se a 212.690 mil ha, com uma variação negativa de $6,87 \%$. Este resultado se refletiu na produção que também variou de $-1,96 \%$, refletindo no aumento dos preços do trigo no período. O consumo, por sua vez, apresentou uma variação positiva embora insuficiente para manter o nível do consumo per capita.

No mercado de commodities como o trigo, a variável norteadora das decisões de abastecimento e regulação de mercado é a razão entre o trigo estocado e o consumo. Esta relação mostra-se historicamente declinante e com o maior coeficiente de variação, causada praticamente pelo estoque, pois o consumo foi muito baixo.

Com base nas informações da Tabela 1 deduz-se que o mercado de trigo apresentou comportamento estável ao longo do período estudado, uma vez que o 
coeficiente de variação das variáveis área, produção e consumo situou-se abaixo de
$5 \%$ e para preço e estoque, que são mais voláteis, abaixo dos $20 \%$.

Tabela 1. Produção mundial de trigo: 1997 a 2007, em mil toneladas métricas.

\begin{tabular}{l|c|c|c|c|c|c|c}
\hline Ano & $\begin{array}{c}\text { Área } \\
\text { Colhida } \\
\text { (mil ha) }\end{array}$ & Produção & Consumo & $\begin{array}{c}\text { Consumo } \\
\text { per capita }\end{array}$ & $\begin{array}{c}\text { Estoque } \\
\text { Final }\end{array}$ & $\begin{array}{c}\text { Relação: } \\
\text { estoque/ } \\
\text { consumo }\end{array}$ & Preço (US\$/t) \\
\hline $1997 / 1998$ & 228.385 & 609.959 & 576.806 & 98,7 & 197.109 & $34 \%$ & 150,8 \\
$1998 / 1999$ & 225.054 & 589.960 & 577.761 & 97,6 & 208.055 & $36 \%$ & 119,4 \\
$1999 / 2000$ & 215.377 & 585.817 & 581.507 & 97,0 & 208.909 & $36 \%$ & 113,5 \\
$2000 / 2001$ & 217.570 & 581.500 & 582.502 & 95,9 & 206.524 & $35 \%$ & 111,8 \\
$2001 / 2002$ & 214.663 & 581.138 & 585.024 & 95,1 & 202.678 & $35 \%$ & 118,4 \\
$2002 / 2003$ & 214.574 & 567.643 & 603.499 & 97,0 & 166.562 & $28 \%$ & 138,4 \\
$2003 / 2004$ & 209.883 & 554.595 & 581.217 & 92,3 & 132.730 & $23 \%$ & 148,7 \\
$2004 / 2005$ & 218.874 & 628.855 & 609.061 & 95,5 & 151.442 & $25 \%$ & 122,1 \\
$2005 / 2006$ & 218.100 & 618.458 & 619.263 & 96,0 & 145.693 & $24 \%$ & 129,6 \\
$2006 / 2007 * * *$ & 212.690 & 598.001 & 615.594 & 94,3 & 128.419 & $21 \%$ & - \\
\hline Média & 217.517 & 591.593 & 593.223 & 95,94 & 174.812 & 29,7 & 128,1 \\
C.V\% & 2,56 & 3,85 & 2,81 & 1,89 & 19,00 & $20 \%$ & 11,49 \\
\hline
\end{tabular}

Fonte: USDA - Departamento de Agricultura dos Estados Unidos, apud Agrianual (2007).

No caso da produção brasileira, tem-se o balanço da oferta e demanda do trigo representado na Tabela 2. Observa-se que a variável consumo mostrou o mesmo comportamento estável do mercado mundial, porém a produção exibiu coeficiente de variação acima de $36 \%$, considerado alto. Os estoques brasileiros também exibem alta variação, o que indica a instabilidade da política agrícola de produção e comercialização desse produto.

A produção brasileira de trigo é inferior às necessidades de consumo. A ABIMA (2008) estima que, só no uso da panificação, o consumo de trigo chega a 10 milhões de toneladas. Embora o Brasil tenha condições de clima e solos favoráveis à produção do trigo, a política de apoio à produção e substituição das importações sofre, a cada período, mudanças que tornam a atividade não competitiva em relação aos países produtores do cereal como a Argentina.

Com relação à substituição da farinha de trigo na produção de massas alimentícias, resultados de pesquisas apontam sobre a possibilidade de substituir a massa de trigo pela do arroz, já que esta última chega a substituir até $100 \%$ do trigo na preparação de massas de biscoitos e macarrão, além de que o Brasil possui considerável produção de arroz, cujo excedente pode vir a substituir o trigo. 
De acordo com a Tabela 3, o estado do Pará importou uma média de 147.058.238,6 toneladas, entre 2000 e junho de 2009, ou seja, 2,47\% do total brasileiro importado, o que corresponde a 5.962.455.000,1 toneladas. No final da série, observa-se que as importações caíram tanto para o Brasil como para o Pará, no entanto o seu valor monetário aumentou substancialmente, em função da crise mundial.

Tabela 2. Balanço da oferta e demanda do trigo, em 1.000 t, Brasil: safras 2001/2002 a 2007/2008.

\begin{tabular}{c|c|c|c|c|c|c|c}
\hline Safra & Estoque Inicial & Produção & Importação & Suprimento & Consumo & Exportação & Estoque final \\
\hline $2001 / 2002$ & 715,9 & $3.194,2$ & $7.045,7$ & $10.955,8$ & $10.180,2$ & 2,1 & 773,5 \\
$2002 / 2003$ & 773,5 & $2.913,9$ & $6.853,2$ & $10.540,6$ & $10.240,5$ & 3,9 & 296,2 \\
$2003 / 2004$ & 296,2 & $6.073,5$ & $5.707,5$ & $11.732,4$ & $10.314,1$ & $1.372,1$ & 391,0 \\
$2004 / 2005$ & 391,0 & $5.845,9$ & $5.311,0$ & $11.547,9$ & $10.433,0$ & 1,7 & $1.113,2$ \\
$2005 / 2006$ & $1.113,2$ & $4.873,1$ & $6.266,1$ & $12.252,4$ & $10.839,8$ & 786,3 & 626,3 \\
$2006 / 2007$ & 626,3 & $2.233,7$ & $7.626,0$ & $10.486,0$ & $10.243,4$ & 21,0 & 221,6 \\
$2007 / 2008$ & 221,6 & $3.823,3$ & $6.433,3$ & $10.478,2$ & $10.175,9$ & 21,0 & 281,3 \\
\hline Média & 591,1 & 4136,8 & 6463,26 & 11141,9 & 10346,7 & 315,44 & 529,01 \\
C.V\% & 52,88 & 36,01 & 12,28 & 6,36 & 2,27 & 173,89 & 61,72 \\
\hline
\end{tabular}

Fonte: Conab - Levantamento: Ago/2007. Período: Trigo (Agosto/Julho).

Tabela 3. Importação do produto trigo pelo Brasil e Estado do Pará: 2000 a jun/2009.

\begin{tabular}{ccccc}
\hline \multirow{2}{*}{ Anos } & \multicolumn{2}{c}{ Brasil } & \multicolumn{2}{c}{ Estado do Pará } \\
\cline { 2 - 5 } & Quantidade (t) & Valor (US\$) & Quantidade (t) & Valor (US\$) \\
\hline 2000 & 7.449 .970 .739 & 855.378 .556 & 160.720 .730 & 18.495 .134 \\
2001 & 6.988 .861 .632 & 868.969 .037 & 178.844 .560 & 226.725 .532 \\
2002 & 6.532 .132 .309 & 872.738 .039 & 179.270 .708 & 23.126 .921 \\
2004 & 6.584 .529 .251 & 1.006 .254 .655 & 190.887 .322 & 28.677 .957 \\
2005 & 4.837 .765 .085 & 728.565 .192 & 165.256 .000 & 25.833 .987 \\
2006 & 4.974 .066 .003 & 647.312 .742 & 119.360 .459 & 15.526 .202 \\
2007 & 6.528 .263 .131 & 988.126 .449 & 114.953 .000 & 17.084 .025 \\
2008 & 6.624 .894 .485 & 1.388 .773 .468 & 164.674 .495 & 35.021 .305 \\
Jun/2009 & 6.022 .234 .187 & 1.871 .298 .464 & 143.715 .112 & 43.807 .844 \\
\hline MÉDIA & 3.081 .833 .179 & 647.978 .629 & 52.900 .000 & 11.643 .052 \\
\hline
\end{tabular}

Fonte: Sistema aliceweb, do MDIC, 2009. 
Finalmente, embora não se tenha informações sobre dados de quantidade produzida e comercializada de macarrão, sabe-se que a principal matéria-prima do macarrão é a farinha de trigo. Neste caso, é importante fazer o vínculo entre a farinha de trigo e o macarrão por meio da correlação entre os preços de tais produtos.

O valor do coeficiente de correlação entre os preços destes produtos no período analisado foi de 0,64, indicando que as duas séries de preços evoluem na mesma direção, ou seja, preços altos da farinha de trigo estão associados com preços também altos para o macarrão e vice-versa.

\section{MATERIAL E MÉTODOS}

Os dados básicos utilizados são preços médios pagos pelo produto macarrão no mercado varejista do estado do Pará, obtidos da Secretaria de Planejamento, Orçamento e Finanças do Estado do Pará (SEPOF), compreendendo uma série temporal que vai de janeiro de 2000 até junho de 2007. Conforme Homma e Santos (1980), Santana (2003) e Rebello et al. (2003), os modelos clássicos de análise temporal permitem fazer a decomposição das informações contida nas séries de dados em quatro componentes básicos, conforme descrito por Rufino (1996) apud Rebello et al. (2003), para a forma multiplicativa adotada neste trabalho: a) Variação de longo prazo ou tendência $\left(\mathrm{T}_{\mathrm{t}}\right)$;

b) Variação cíclica $\left(\mathrm{C}_{\mathrm{t}}\right)$;

c) Variação estacional $\left(S_{t}\right)$ e;

d) Variação aleatória $\left(\mathrm{A}_{\mathrm{t}}\right)$

Matematicamente essas variações são representadas, na forma multiplicativa, pela seguinte expressão:

(1) $P_{t}=T_{t} \times C_{t} \times S_{t} \times A_{t}$

Em que $\mathrm{P}_{\mathrm{t}}$ é a variável preço do macarrão no mercado varejista do Pará, deflacionado pelo IGP-DI da Fundação Getúlio Vargas. As demais variáveis já foram definidas anteriormente.

Neste modelo, conforme Fonseca et al. (1995), as forças relativas às componentes (Tendência, Ciclo, Estacional e Aleatória) atuam proporcionalmente em nível geral da série.

Para se determinar os índices estacionais de preço, faz-se o uso do método da média aritmética móvel centrada em 12 meses (NEWBOLD, 1994 apud SANTANA, 1996; REBELLO et al., 2003), para separar as variações sazonais e aleatórias presentes nos dados originais e deixar apenas os efeitos das componentes tendências e cíclicas da série:

(2) $M M_{t}=T_{t} x C_{t}$ 
O cálculo da média móvel centrada nos 12 meses foi realizado conforme indicado por Santana (1996) e Hoffmann (1998):

(3) $\quad \mathrm{MM}_{\mathrm{t}}=1 / 12\left(\mathrm{P}_{\mathrm{t}-6}+\mathrm{P}_{\mathrm{t}-5}+\ldots+\mathrm{Pt}+\right.$ $\left.\mathrm{P}_{\mathrm{t}+1} \ldots+\mathrm{P}_{\mathrm{t}+5}\right)$

Os índices estacionais mensais são obtidos dividindo-se a série original mensal do preço do macarrão, pela média móvel correspondente, a saber:

(4) $I E S=P_{t} / M M_{t}=T_{t} \times C_{t} \times S_{t} \times A_{t} /$ $T_{t} \times C_{t}=S_{t} \times A_{t}$,

Sendo o IES encontrado denominado de Índice Estacional Simples. A obtenção do IES encontrado anteriormente ainda apresenta em sua estrutura a componente aleatória. Para eliminá-la, adota-se o processo indicado por Karmel e Polasek (1973) e Santana (2003), que consiste em calcular uma média aritmética dos índices simples para cada mês. O valor encontrado é o IEM (índice estacional médio):

$$
I E M_{t}=\sum I E S_{t} / n
$$

Duas propriedades são destacadas neste método:

a) A somatória dos índices estacionais é igual a 1.200;

b) A média dos índices estacionais é igual a 100 .
Caso os resultados não atendam essas duas condições acima, utiliza-se a seguinte fórmula para o ajustamento:

$$
I E P_{t}=\operatorname{IEM} x\left(1200 / \Sigma I E S_{t}\right)
$$

Finalmente, para mensurar as flutuações dos índices estacionais em torno da média, calcula-se o desvio padrão para cada mês e, a seguir, se estabelecem os limites de confiança superior e inferior, que são obtidos a partir da soma e subtração ao índice estacional do preço ajustado ao valor do desvio padrão.

\section{RESULTADOS E DISCUSSÃO}

A análise dos resultados da componente tendência, média móvel, índice cíclico e índice sazonal serão apresentados em seguida.

\section{COMPONENTE TENDÊNCIA}

Inicialmente, fez-se a análise comportamental dos dados na forma original e a linha de tendência.

O comportamento da série exibe três padrões bem definidos na Figura 1:

a) $\mathrm{O}$ primeiro mostra uma queda nos preços entre janeiro de 2000 e maio de 2001;

b) O segundo período inicia em maio de 2001 em que os preços aumentam fortemente até atingir o patamar mais alto que perdura ao longo do primeiro semestre de 2003; 
c) O terceiro padrão de comportamento, considerado dominante por sua extensão, vai de junho de 2003 a junho de 2006, quando a série começa a se estabilizar nesse patamar. A linha de tendência ao longo do período como um todo, apresenta-se decrescente.

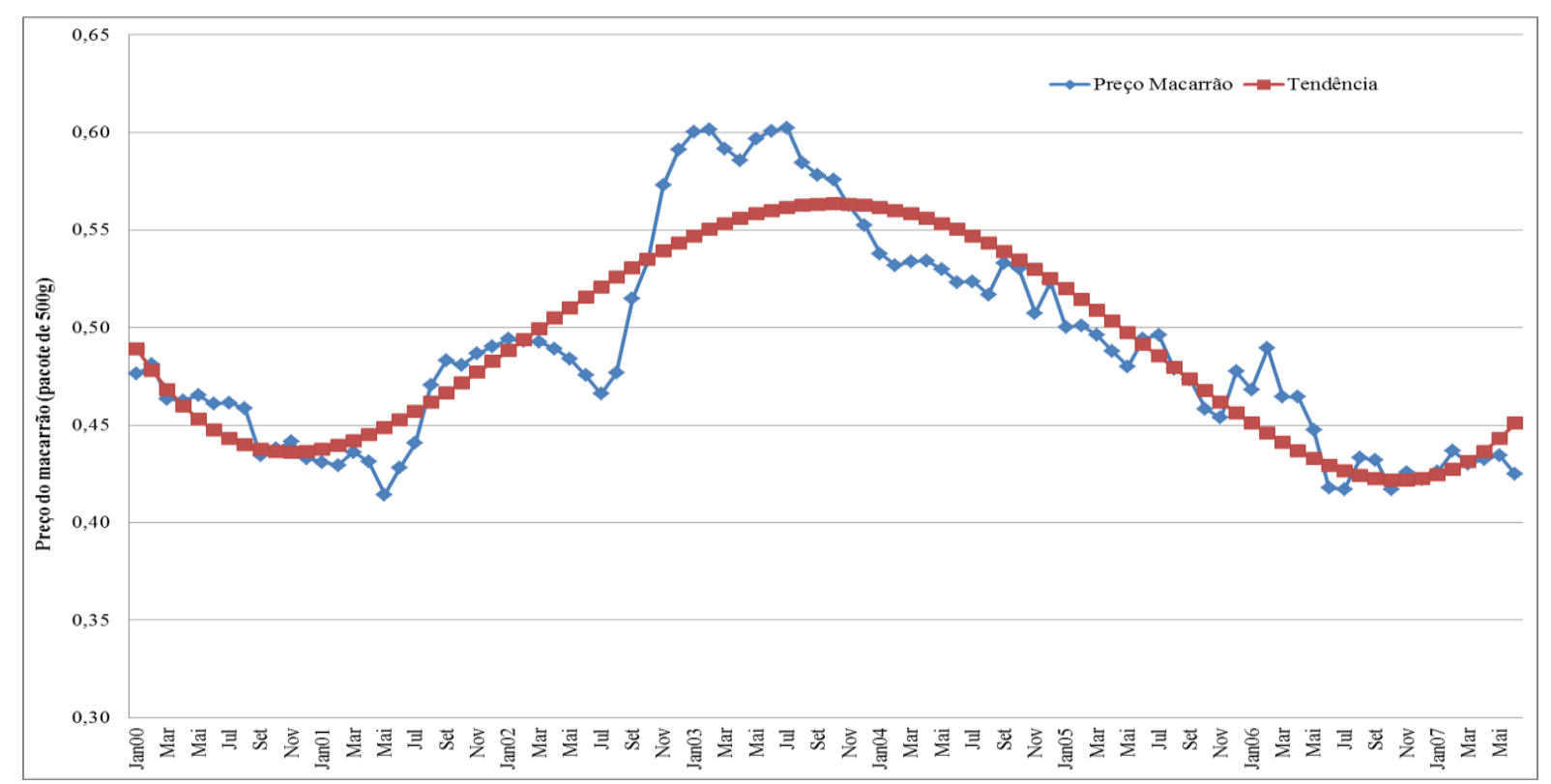

Figura 1. Preços originais e linha de tendência da série de preços do macarrão, pacote de 500g: 2000 a 2007.

Fonte: Dados da pesquisa.

As variações comportamentais da tendência ocorrem, geralmente, em função das interações entre a oferta e a demanda. No período em que a demanda de macarrão cresce mais rapidamente do que a oferta, os preços tentem a aumentar como no período entre 2001 a 2003. Todavia, quando a oferta aumenta mais rapidamente do que a demanda, os preços tendem a cair como no período iniciado em junho de 2003. Estes efeitos se processam, conforme Santana (2005) pela mudança no poder aquisitivo e nos gostos e preferências dos consumidores, no lado da demanda, e por mudanças na tecnologia de processo e de produto, no lado da oferta. No caso do macarrão, ocorreram todas essas mudanças em conjunto, em função dos efeitos do Plano Real.

\section{MÉDIA MÓVEL}

Por suas características, a MM elimina as variações aleatórias e sazonais dos preços, passando a exibir apenas o 
comportamento sistemático dos preços, definidos pelas componentes de tendência e cíclico. Ou seja, a MM suaviza o comportamento das séries (SANTANA; RODRIGUES JÚNIOR, 2000). Observa-se que a MM exibe o mesmo comportamento da série original, porém sem as variações sazonais e aleatórias, o que torna a série suave (Figura 2).

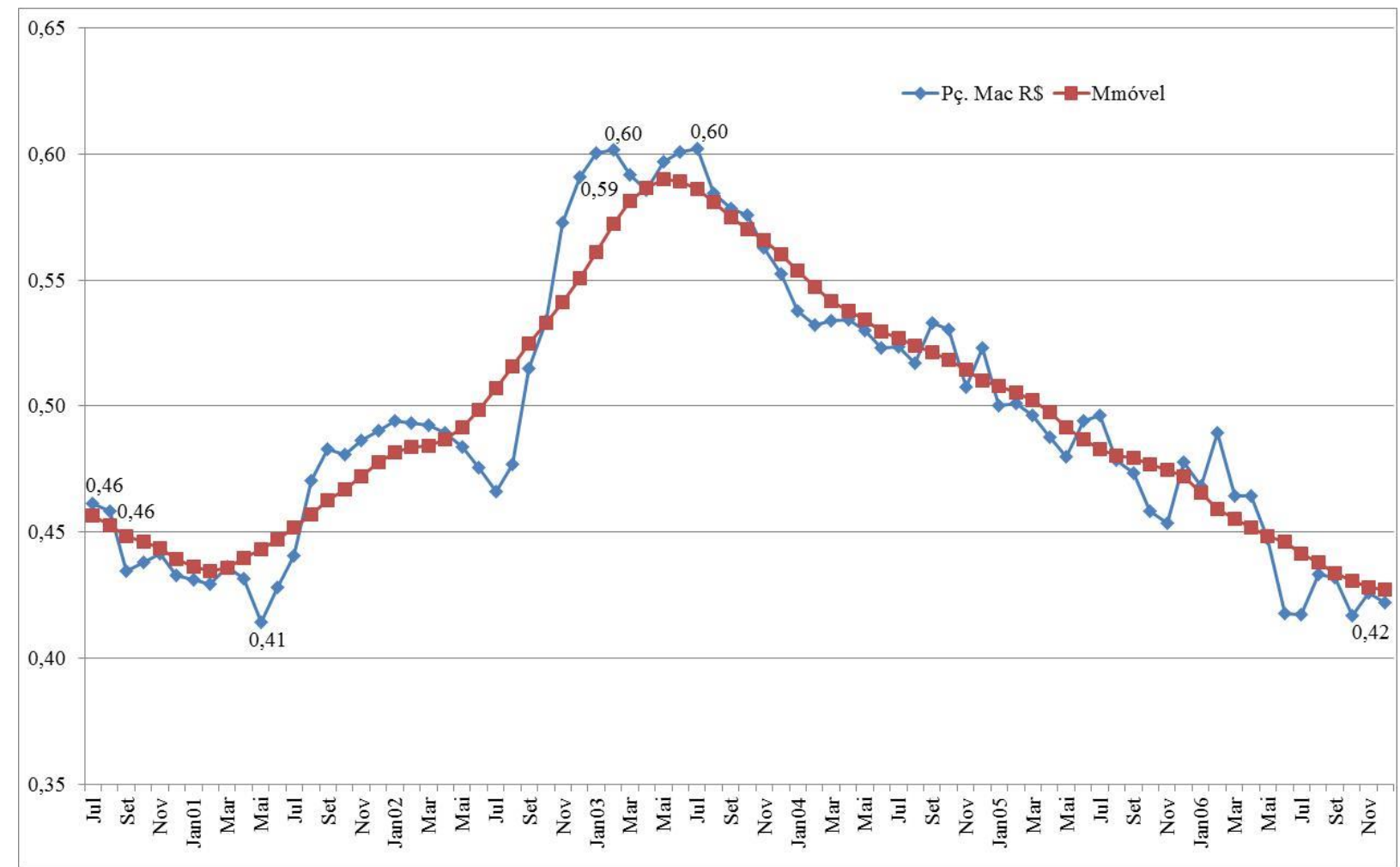

Figura 2. Preço deflacionado e Média Móvel (MM) do produto macarrão, no período de jan. 2000 a jun. 2007.

Fonte: Dados da pesquisa.

\section{ÍNDICE CÍCLICO}

O índice cíclico (IC) mostra os efeitos do comportamento inercial no tempo da economia, envolvendo as expansões e retrações sobre o macarrão.

$\mathrm{Na}$ Figura 3 estão evidenciadas as fases de crescimento e decréscimo dos preços do macarrão, de modo a caracterizar dois ciclos no período analisado.

Os ciclos são definidos como a distância temporal entre dois picos ou dois vales consecutivos. $\mathrm{O}$ primeiro ciclo inicia em julho de 2000, atinge o fundo do vale 
em maio de $2002(96,31 \%)$ e novo pico em julho de 2003 (105,72\%). O segundo ciclo inicia-se em julho de 2003 e se prolonga até julho de 2006, sendo que o fundo do vale ocorreu em maio de 2004 (96,24\%). Observa-se que embora os ciclos tenham a mesma amplitude de três anos, no primeiro, o período de queda foi mais prolongado do que no segundo.
Estes resultados indicam que 0 movimento ciclo do preço do macarrão demora três anos para se completar, portanto as estratégias de longo prazo com relação ao produto, envolvendo o planejamento de novas plantas devem atentar para este comportamento.

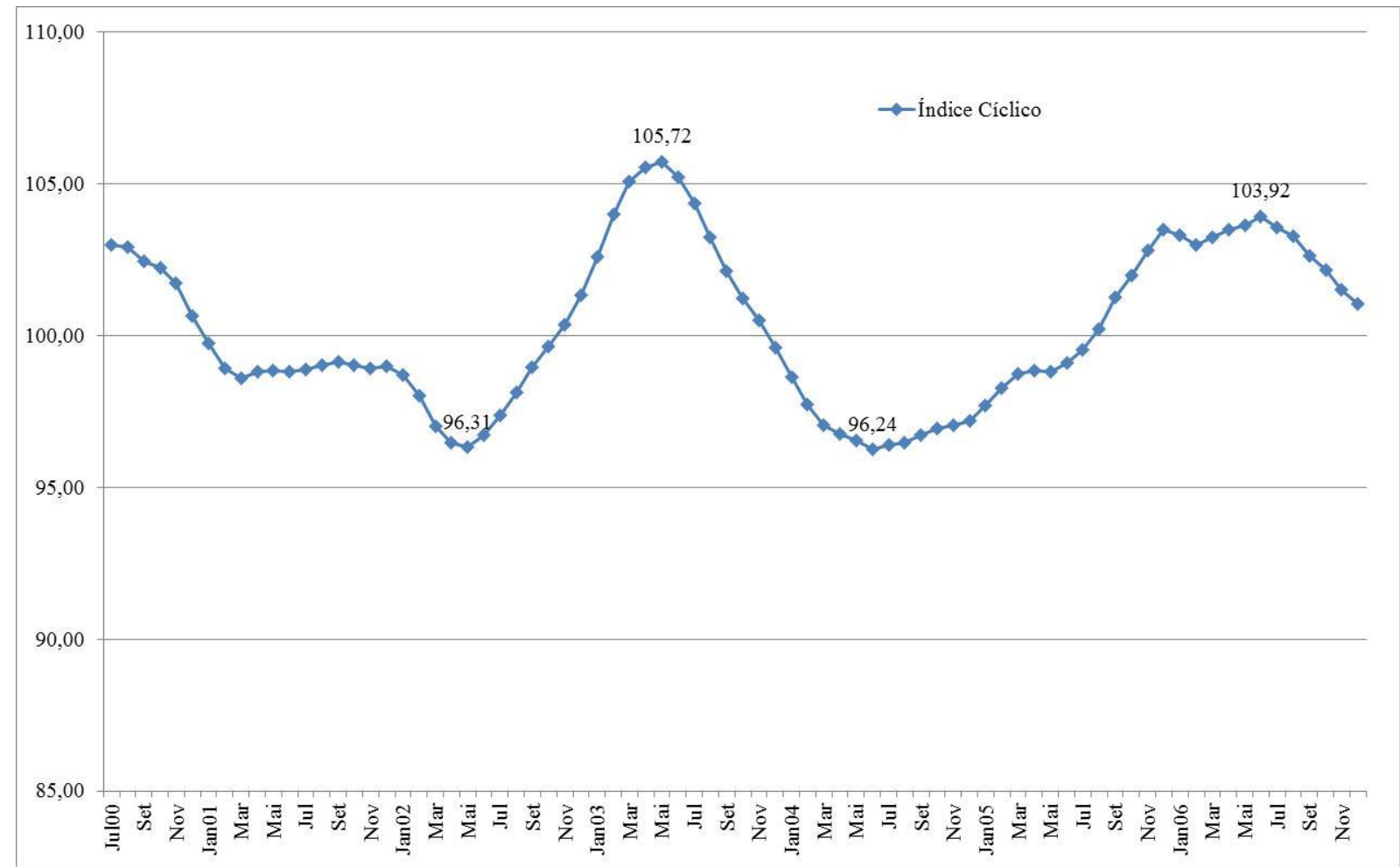

Figura 3. Índice Cíclico (IC) do preço do macarrão, jul./2000 a nov./2006.

Fonte: Dados de pesquisa.

\section{ÍNDICE SAZONAL}

De acordo com os resultados da Tabela 4, o maior IEV foi $101,66 \%$ e o menor foi $98,04 \%$, respectivamente nos meses de fevereiro e junho, com uma amplitude de variação de apenas 3,62\%.
Os menores preços do macarrão ocorrem no período que vai de abril a julho e, os maiores vão de setembro a março, embora outubro apareça como um mês atípico, pois o preço diminui. 
Com relação à variabilidade dos preços em torno média, o maior desvio padrão ocorre em julho $(4,16)$ e menor em março $(1,57)$. Isto não garante, de modo linear, que nesses meses se terá o maior valor (limite superior), mas para o limite inferior, o desvio padrão é determinante para este $(94,58 \%)$.

Tabela 5. Índice Estacional Médio (IEM), Desvio Padrão (Desv.Pad), Índice Estacional Verdadeiro (IEV) e Limites Superior e Inferior (LIM SUP e LIM INF).

\begin{tabular}{l|c|c|c|c|c}
\hline & IEM & Desv.Pad & IEV & LIM SUP & LIM INF \\
\hline Janeiro & 100,73 & 3,60 & 100,93 & 104,53 & 97,33 \\
Fevereiro & $\mathbf{1 0 1 , 4 5}$ & 3,75 & $\mathbf{1 0 1 , 6 6}$ & $\mathbf{1 0 5 , 4 0}$ & 97,91 \\
Março & 100,49 & 1,57 & 100,68 & 102,25 & 99,12 \\
Abril & 99,75 & 1,75 & 99,95 & 101,70 & 98,20 \\
Maio & 98,29 & 2,63 & 98,49 & 101,12 & 95,86 \\
Junho & $\mathbf{9 7 , 8 4}$ & 3,45 & $\mathbf{9 8 , 0 4}$ & 101,49 & 94,59 \\
Julho & 98,55 & 4,16 & 98,74 & 102,90 & $\mathbf{9 4 , 5 8}$ \\
Agosto & 99,20 & 3,33 & 99,40 & 102,73 & 96,06 \\
Setembro & 100,08 & 2,59 & 100,28 & 102,86 & 97,69 \\
Outubro & 99,64 & 2,67 & 99,83 & 102,50 & 97,16 \\
Novembro & 100,22 & 3,32 & 100,42 & 103,74 & 97,10 \\
Dezembro & 101,39 & 3,18 & 101,59 & 104,77 & 98,41 \\
\hline Total & $\mathbf{1 . 1 9 7 , 6 3}$ & & $\mathbf{1 . 2 0 0 , 0 0}$ & & \\
\hline
\end{tabular}

Fonte: Dados da pesquisa.

$\mathrm{Na}$ Figura 4 pode-se visualizar que o período de maior produção do macarrão ou período de safra ocorre entre os meses de abril a agosto, em que os valores do IEV situam-se abaixo do índice médio (100). Neste período os moinhos tendem a operar com maior capacidade para atender ao incremento do consumo de massas em geral e do macarrão em particular. $\mathrm{O}$ menor preço atingido neste período ocorreu no mês de junho.
O período de menor oferta do macarrão ou entressafra foi definido entre os meses de setembro a março, quando o IEV situa-se acima do índice médio (100). A amplitude de variação do índice, diferença entre o maior valor $(101,59)$ e menor valor $(98,04)$ é de $3,55 \%$, mostrando uma baixa variação dos preços dentro do ano, o que se reflete em baixo risco de variação dos preços do macarrão. $\mathrm{Na}$ verdade, como o macarrão é um produto industrializado e com longo 
período de prateleira, assim como também a farinha do trigo apresenta baixa perecibilidade, o preço apresenta alta estabilidade ao longo do ano.

$\mathrm{O}$ risco de preço, avaliado por meio do desvio padrão, indica que há dois períodos de maior instabilidade: um na safra, que compreende os meses de junho a agosto, com pico em julho; outro na entressafra, que se prolonga de novembro a fevereiro, com pico em janeiro (Tabela 4).

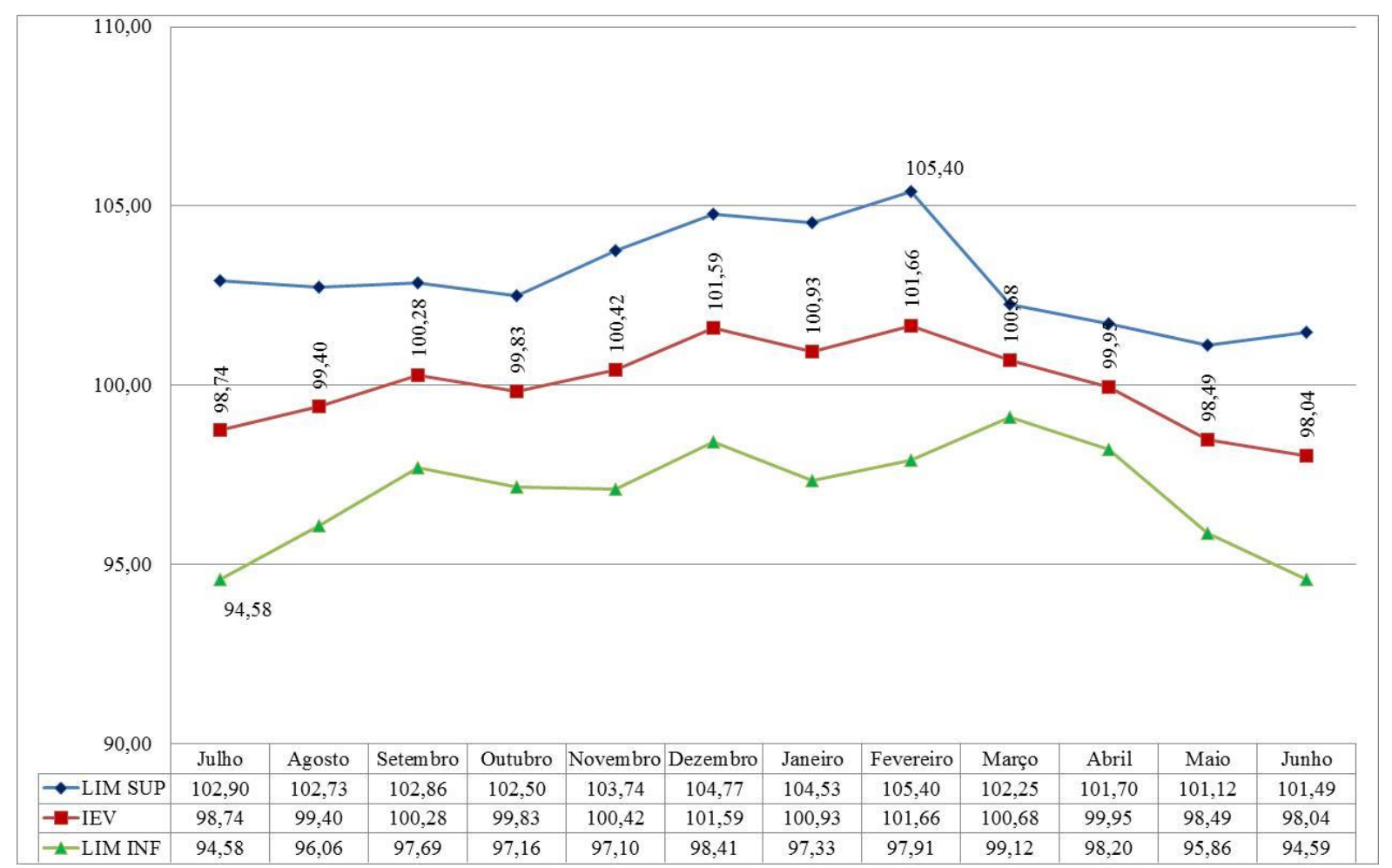

Figura 4. IEV, limites superior e inferior da série de preços do macarrão.

Fonte: Dados da pesquisa.

\section{CONCLUSÃO}

Os resultados do trabalho, pioneiramente, permitiram a disponibilização de informações cruciais para a tomada de decisão dos agentes que atuam na cadeira produtiva do macarrão, ao mostrar o comportamento cíclico do produto, que se completa em três anos e o comportamento sazonal dos preços do produto, com baixa instabilidade ao longo do ano.

A maior oferta de macarrão ou período de safra ocorre entre os meses de abril a agosto, em que os valores situam-se abaixo do índice médio. A entressafra, por sua vez, foi definida entre os meses de 
setembro a março, quando o os preços do macarrão se situam acima do índice médio. Este período se configura pela maior escassez de matéria-prima para sua fabricação.

A análise de sazonalidade dos preços do macarrão indicou que os índices estacionais apresentaram valores entre $101,59 \%$ a $98,04 \%$, o que corresponde a uma amplitude de 3,55\%, indicando alta estabilidade de preços no varejo. A maior variabilidade no período da safra, medida pelo desvio padrão, ocorreu no mês de julho e a maior variação da entressafra foi registrada no mês de janeiro.

\section{REFERÊNCIAS}

ABIMA (Associação Brasileira das Indústrias de Massas Alimentícias). Eu amo macarrão. Disponível em: 〈http://www.abima.com.br>. Acesso: set. 2008.

AGRIANUAL 2007: Anuário da Agricultura Brasileira. São Paulo: FNP Consultoria e Comércio, 2007.

Brasil lidera as importações mundiais de trigo. Informativo Técnico da Revista Gleba. Ed. Jan./Fev.2002. Disponível: <http://www.cna.org.br/gleba02>. Acesso: jun.2007.

CONAB. Acompanhamento da safra brasileira: grãos. Décimo primeiro levantamento ago./2007. Disponível: <htttp://www.conab.gov.br>. Acesso: jan. 2008

FONSECA, J. S.; MARTINS, G. de A.; TOLEDO, G. L. Estatística aplicada. São Paulo, Atlas, 1995.

IBGE. Dados da produção de trigo no Brasil e demais regiões. SIDRA.IBGE., 2008. Disponível em: <sidra.ibge.gov.br>. Acesso: nov.2008.

HOFFMANN, R. Estatística para economistas. 3. ed. São Paulo: Pioneira, 1998. $430 \mathrm{p}$.

HOMMA, A. K. O.; SANTOS, A. I. M. Análise da estacionalidade de preços de produtos agropecuários nos Estados do Acre, Amazonas e Pará. Belém: EMBRAPA/CPATU, 1980. 79 p. (Circular Técnica, 7).

KARMEL， P. H.; POLASEK, M. Estatística geral e aplicada à economia. São Paulo: Atlas, 1973.

LATORRE, M. do R. D. de O.; CARDOSO, M. R. A. Time series analysis in epidemiology: an introduction to methodological aspects. Revista Brasileira de Epidemiologia, v.4, n.3, p.145-152, 2001.

MINISTÉRIO DO DESENVOLVIMENTO, INDÚSTRIA E COMÉRCIO EXTERIOR - MDIC. Dados da importação do produto trigo pelo Brasil e Estado do Pará. 2009. 
Disponível em: <www.mdic.gov.br>. Acesso: set. 2009.

Moinhos brasileiros antecipam importação de trigo. Disponível em: <http://www.seder.mt.gov.br>. Acesso: 20 ago. 2008.

REBELLO, F. K.; REALLE FILHO, H. B.; FIGUEIREDO, R. N. C. Diagnóstico e perspectiva econômica da cadeia produtiva do coco-da-baía no Estado do Pará. In: O meio amazônico em desenvolvimento: exemplos de alternativa econômica. Belém: Banco da Amazônia, Gerin, 2003. SAMORA, R. Dias Branco deve comprar mais trigo na América do Norte em 2007. Disponível em: $<$ http://noticias.uol.com.br/economia/cotac oes>. Acesso: jul. 2007.

SANTANA, A. C. de. Análise de preços agrícolas. Cadernos Sócio-Econômicos, v. 2, n. 2, p. 1-20, ab./jun. 1996.

SANTANA, A. C. de. Elementos de economia, agronegócio e desenvolvimento local. Belém, GTZ; TUD; UFRA, 2005.
SANTANA, A. C. de. Métodos quantitativos em economia: elementos e aplicações. Belém: UFRA, 2003.

SANTANA, A. C. de; AMIN, M. M. Cadeias produtivas e oportunidades de negócio na Amazônia. Belém: UNAMA, 2002.

SANTANA, A. C. de; RODRIGUES JÚNIOR, H. Análise da sazonalidade de preços de frutas comercializadas na CEASA de Belém, no período de 1990 a 1998. Movendo idéias. Belém: UNAMA, v. 5, n. 8, p. 22-34. Dez. 2000.

SERRANO, R. L. Pão amargo: a alta dos cereais e de outros alimentos pode despertar o dragão inflacionário. América economia. v. 17, n. 347, set. 2007. Disponível em: <www.amercicaeconomia.com.br>. Acesso: ago. 2007. 